\title{
STUDY OF WATER POLLUTION EARLY WARNING FRAMEWORK BASED ON INTERNET OF THINGS
}

\author{
H. Chengfang*, X. Xiao , S. Dingtao, C. Bo, W. Xiongfei \\ Changjiang River Scientific Research Institute, \\ 430010 Wuhan, Hubei,China - \\ huchfang@163.com,(xiaoxiao,shendingtao,caobo,wenxiongfei)@mail.crsri.cn
}

\section{Commission VIII, WG VIII/4}

KEY WORDS: Water Pollution, Early Warning, Automatic Monitoring, Warning Framework, Internet of Things

\begin{abstract}
:
In recent years, with the increasing world environmental pollution happening, sudden water pollution incident has become more and more frequently in China. It has posed a serious threat to water safety of the people living in the water source area. Conventional water pollution monitoring method is manual periodic testing, it maybe miss the best time to find that pollution incident. This paper proposes a water pollution warning framework to change this state. On the basis of the Internet of things, we uses automatic water quality monitoring technology to realize monitoring. We calculate the monitoring data with water pollution model to judge whether the water pollution incident is happen or not. Water pollution warning framework is divided into three layers: terminal as the sensing layer, it with the deployment of the automatic water quality pollution monitoring sensor. The middle layer is the transfer network layer, data information implementation is based on GPRS wireless network transmission. The upper one is the application layer. With these application systems, early warning information of water pollution will realize the high-speed transmission between grassroots units and superior units. The paper finally gives an example that applying this pollution warning framework to water quality monitoring of Beijing, China, it greatly improves the speed of the pollution warning responding of Beijing.
\end{abstract}

\section{INTRODUCTION}

The water ecological environment is important to the human society. Water resource is the most important material and energy of the society foundation. The status of the water ecological environment directly affects the human survival conditions and quality. The water supply affects the human to exploit and utilize resources from all aspects, such as agricultural irrigation, industrial and urban construction. In recent years, with the increasing world environmental pollution happening, flood, drought, water pollution, and water ecological deterioration directly threat to human survival and production activities.And sudden water pollution incident has become more and more frequently in China. It has posed a serious threat to water safety of the people living in the water source area [1].

Conventional water pollution monitoring method is with manual mode, this way is with fixed cycle and longer timeconsuming, the shortcoming of this way is it maybe miss the best time to find that pollution incident. It is urgent to design a set of reasonable and effective decision support system for the management of sudden water pollution monitoring and early warning.

With the rapid development of the Internet of things, it provides the possibility of automatic water pollution monitoring and realize the early warning[2][3]. Early warning system can realize sudden water pollution accident rapid detection, and give an early warning with the accurate analysis, it is great significance for water pollution emergency response and protection.

\section{MATERIALS AND METHODS}

\subsection{Business Process}

Beijing is the capital of China, it has its special important position in China.Beijing is located in the haihe river basin, It is a water resources serious shortage megalopolis. To safeguard water supply security of Beijing is not only directly related to the health and safety of thousands of public, but also related to the capital maintenance, social even, and economic stability of the country.

The major source of drinking water including: Miyun Reservoir, Jingmi Channel, the Chaobai River, the Guanting Reservoir, the Yongding river, Yongding River diversion channels and other small reservoirs.

If water pollution event occurring, processing units involves three levels: The first level is the Beijing Municipal Water Affairs Bureau, the second is Beijing Hydrological Station, the third level is the primary reservoir management units.

The water quality information transfer through these three levels units. The primary reservoir management units responsible for daily water quality monitoring. In the conventional mode, They give a water quality monitoring report to Beijing Hydrological Station by email. Hydrological Station responsible for

\footnotetext{
* Corresponding author
} 
summarizing all the water source of the reports, after finishing analysis of them, take the results reported to the Beijing Municipal Water Affairs Bureau. Process flow is shown in figure 1 .

Once the water pollution incident occur, the information reported to the Beijing Municipal Water Affairs Bureau, experts were gathered to discuss disposal method of the pollution incident.

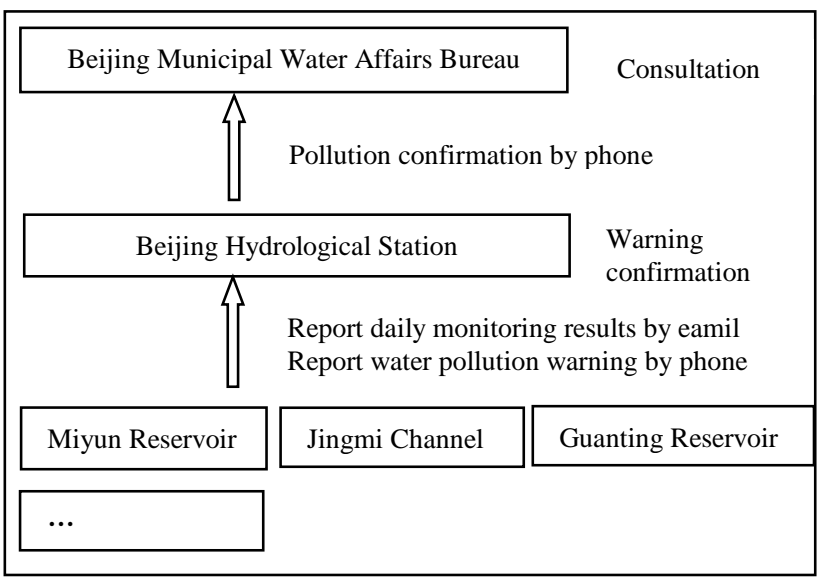

Figure 1. Conventional water quality transmission mode

Although the general Information transmission mechanism can transmit messages timely, but on the base of internet of things technology, it can further improved the efficiency of information transmission.

\subsection{Platform Construction Design}

In this paper, we design three-level hierarchical mechanism to realize water pollution early warning and emergency response.

1. First level: decision making system

2. Second level: warning confirmation system

3. Third level: monitoring system

We design three systems to complete their corresponding job. All these systems are together to realize the goal of ensuring the security of the water source of water. The systems construction design is shown in figure 2 .

The system of the third-level monitoring system is deployed at the corresponding water management unit, such as Miyun Reservoir management unit, Guanting Reservoir management unit, Jingmi Channel Management unit and other basic level managements. The bottom of the system are various sensors that are automatic water detection instruments. They give online water quality monitoring results to the system through wireless data transmission network. On the other way, the system also can intuitive display equipment running status, judging the equipment does work well or not. If equipment break down, the system will send alarm to the administrator. It will help to eliminate equipment failure in time and ensure the system running normally. Therefore, the third-level monitoring system is the basic level of the whole platform, it give the guarantee of the other systems working properly.

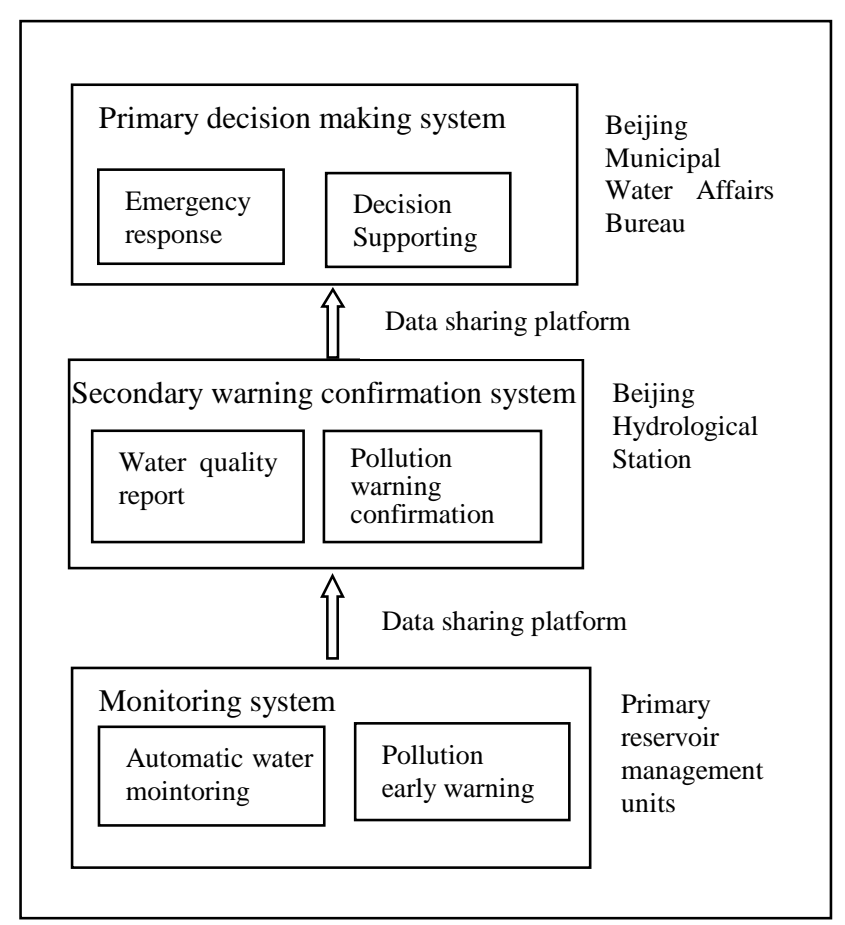

Figure 2. Pollution warning and response platform construction

The name of the second level system is secondary warning confirmation system. This system deploy at hydrological station or tap water group. These two units are on the secondary level in the water management hierarchy. The major purpose of secondary warning confirmation system is to summarize all the information of water quality monitoring sites. The system sets the boundary conditions of water quality index, then the system judge the water quality data with the boundary conditions. If a record is out of the boundary value, that means the system regard this record as a warning record, it shows that water pollution incident maybe happened. In this part, it need to field investigation combined with artificial judgment. If the water pollution really happened, it will trigger message delivery mechanism, send alert warning to the first level system.

The name of the first level system is primary decision making system. This system deploy at Municipal Water Affairs Bureau. The system receive the water quality reports every day, and Water pollution alert information. Once alert arrive, Municipal Water Affairs Bureau should organize water expert consultation to discuss countermeasures. Early warning information disposal will return to the secondary warning confirmation system through the data sharing platform.

Data sharing platform responsible for connecting these three systems, do the data transfer among the systems, it has a very important role that to keep the data consistency among these systems, it also need ensure that the data real-time synchronization. 


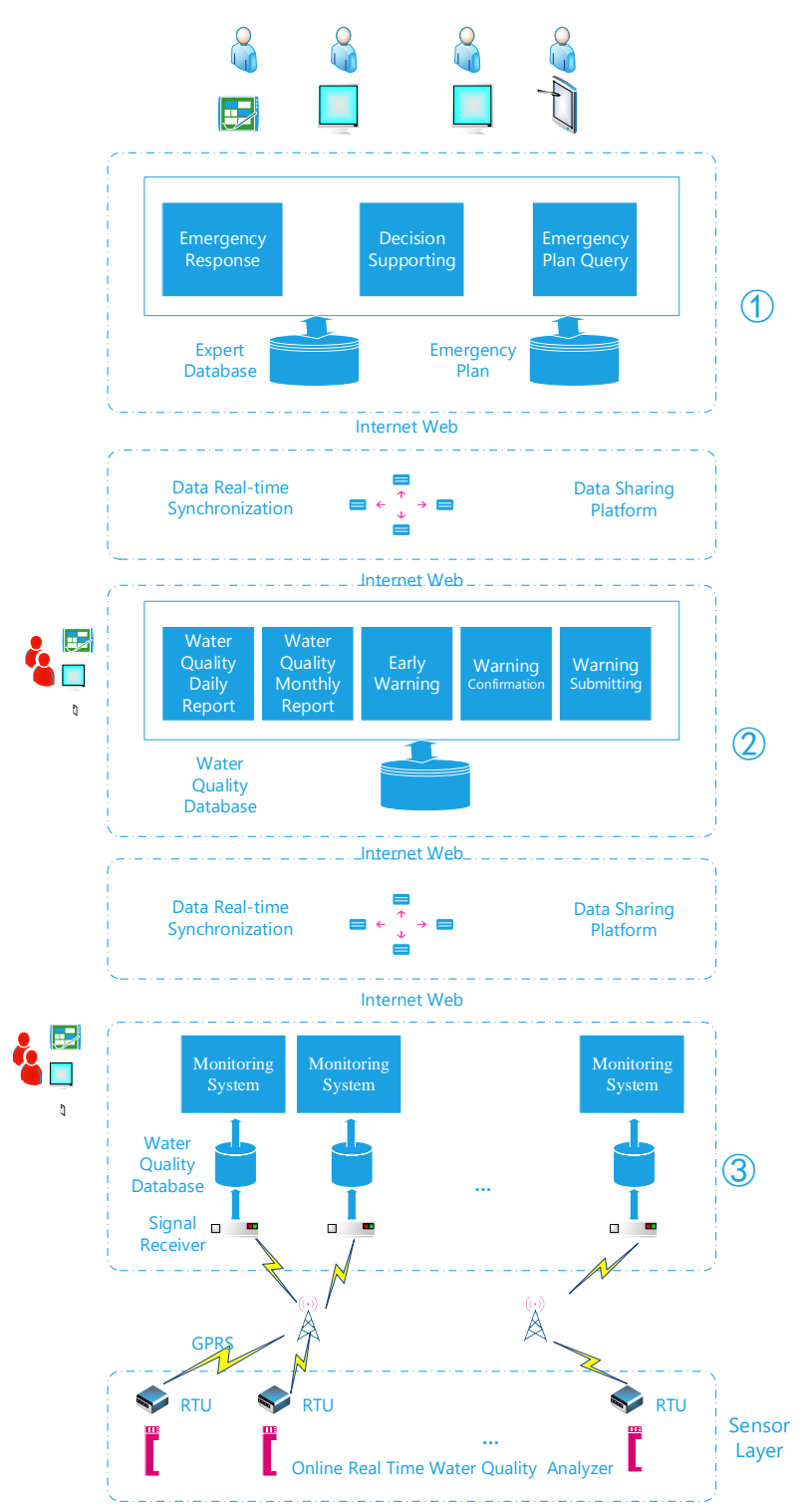

Figure 3. The platform construction

As the analysis above, we design the platform construction as the figure 3 .

\subsection{Workflow of Warning Confirmation}

Warning confirmation processing is important content of the whole platform.

The process of water quality early warning is divided into the following steps: early warning, artificial confirmation and alert disposal.

In the past, it used the conventional artificial testing method to check the water quality. In this case, it was with fixed time and cycle. If the water pollution event happened, there are two ways to find the pollution. The one way is depending on artificial detection of water staff, the other way is that the crowd living along the river found pollution, and send this information to the water management agency.

Real time online automatic water quality monitoring technology has changed all that. Online automatic monitoring shorten the time of the pollution discovery. Its monitoring time interval can be shortened to a few minutes according to site condition. It ensure the sustainability of water quality monitoring, and it will catch the best time to find the pollution, and make up the shortfall of the conventional long interval period.

In this platform, there are also two ways to trigger the earlywarning mode, the first one is a kind of traditional way of artificial alarm, another way is to rely on automatic monitoring instrument to generate alert.

The traditional artificial alarm rely on the people around the water source to discover the pollution directly. For example, the surface of the water changed color or the river send out the obvious smell. People report to the local water management agency of this pollution incident, the staff to verify the pollution situation at the scene, if the staff confirm that it really happened, then the platform start alert process.

Automation alarm depend on the information system. It is divided into two steps: the early warning and warning confirmation. The early warning perform by the system automatically. According to the need, we design the early warning into three levels: orange warning, yellow warning and red warning. Their corresponding pollution levels increase in turn.

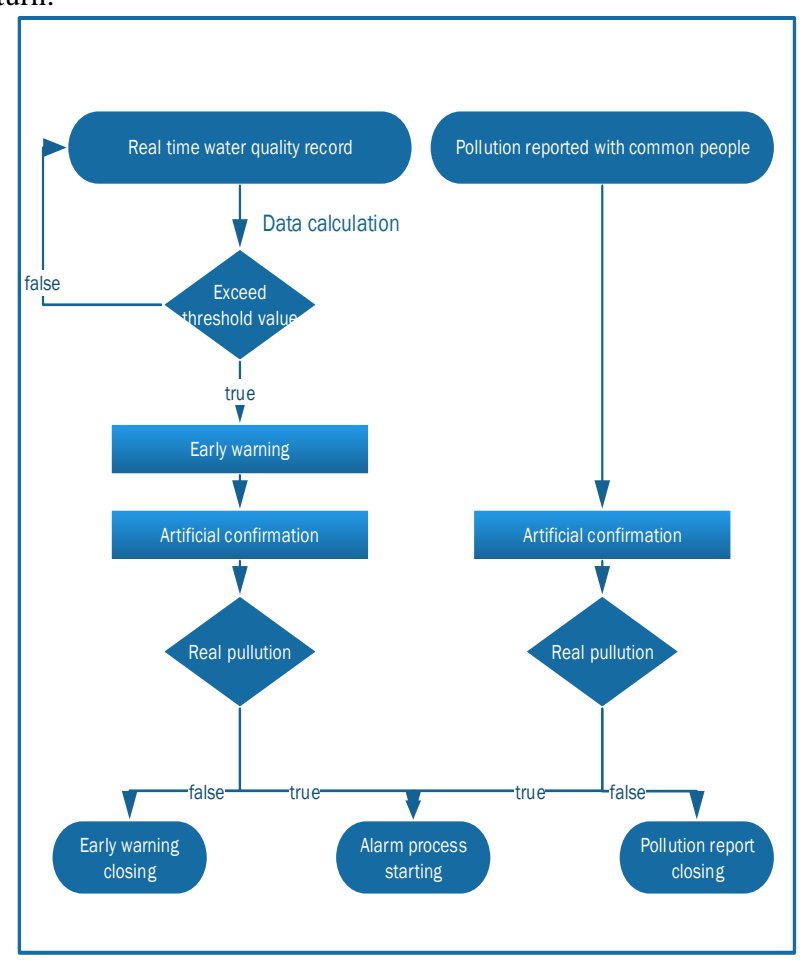

Figure 4. Workflow of pollution warning

\subsection{Threshold Value Setting}

Once one water quality record sending into Secondary Warning Confirmation System, the system give a filtering check first. According to water quality monitoring indicators, the system set up boundary value respectively, compare with the real time data record indicator value with the boundaries, save the results into the database.

Water quality boundary value is mainly according to Chinese Standards for surface water (GB3838-2002). We set III class as 
the early warning boundary value. Early warning corresponding relationship is as follows:
1. III class: Orange warning
2. IV class: Yellow warning
3. V class: Red warning

The main parameter index value are shown in table 1.

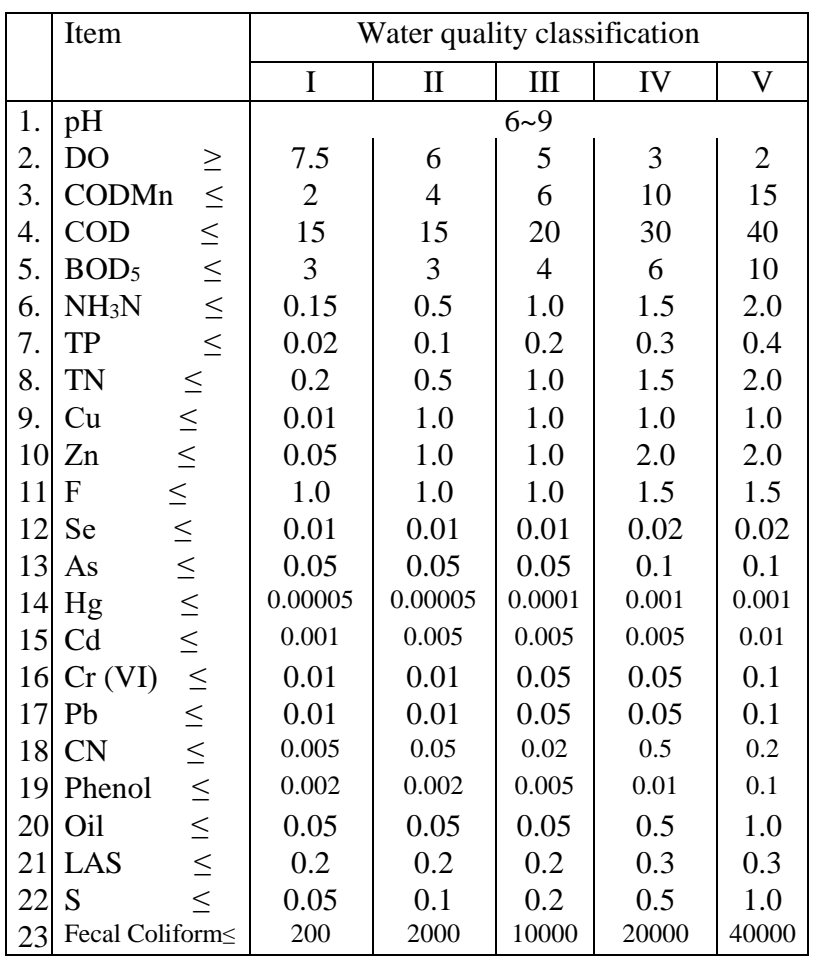

Table 1. Threshold of the main parameters

\section{CONCLUSIONS}

According to the above architecture, water pollution earlywarning platform is realized. The third level system have deployed at several important water sources, and the second system has running at Beijing Hydrological Station. The whole platform has been running in good condition. Figure 4 shows the system interface screenshots of daily monitoring function. The use of the Internet of things technology has changed the conventional way of water quality detection, effectively enhance the detection frequency, shorten the time interval, and increase the timeliness of data. This platform change the information transfer mode among the different agencies of water management and shorten the time of the water pollution event found.



Figure 4. Daily monitoring interface

\section{ACKNOWLEDGEMENTS}

This paper was supported by the National Natural Science Foundation of China (Grant No.41301435, No. 51409021, No. 41501558, No. 41201452).

\section{REFERENCES}

[1] W. Yuexing, Y. Kuihao, L. Gaosong, P. Shenghua, "Environmental risk assessment for the urban drinking water sources : methodology and case study", Journal of Safety and Environment, vol. 5, 2014, pp.316-320.

[2] Z. Yichun, F. Xiujuan, Z. Guangming, "Emergency Monitoring About Sudden Water Pollution Accident in Drinking Water Sources" Yellow River, vol. 8, 2011, pp. 75-77.

[3] T. Weiyan, L. Chunmei, Z. Guocai, "Water Quality Parameters Monitoring System of Data Long-distance Transmission Based on GPRS," Automation and Instrumentation, vol. 7, 2010, pp. 52-55 